\title{
Formulation and Evaluation of Herbal Gel Containing Solanum Nigrum Extract
}

\section{Dr. Nagoba Shivappa N. ${ }^{*}$, Sonkamble Pallavi S. ${ }^{2}$, Sakhare Ram S. ${ }^{2}$, Wadulkar Raghunath D. ${ }^{2}$, Swami Avinash B. ${ }^{2}$}

${ }^{1}$ Associate Professor and Head, Department of Pharmaceutics, Channabasweshwar Pharmacy College, Kava Road, Latur, Maharashtra, India

${ }^{2}$ Department of Pharmaceutics, Channabasweshwar Pharmacy College, Latur, Maharashtra, India *Corresponding author Dr. Nagoba Shivappa, E-mail: nagobashivraj@gmail.com

\begin{abstract}
The aim of present study was to formulate and evaluate herbal gel containing Solanum nigrum extract for prevention of wound healing. Topical gel formulation was designed by using Solanum nigrum extract as API and HPMC E5 as a gelling agent. The herbaceous plant Solanum nigrum (kamuni) reported for healing action and newer research studies and methodologies are being carried to find active chemical constituents which not only promise fast healing but also will reduce the complication and cost. Extracts of this medicinal plant are useful in the treatment of several health problems such as bacterial infections, ulcer, cancer, tuberculosis, arthritis and inflammatory. The plant Solanum nigrum (kamuni) leaves is the best traditional medicine for the study of wound healing activity. The concept of wound healing is changing from day to day. Ayurveda is the richest source of plant drugs for management of wounds and Solanum nigrum L. is one such. The plant is used as haemostatic and wound healing agent from ethno pharmacological point of view. The prepared gel was characterized for their physicochemical parameters i.e., preliminary phytochemical analysis, quantitative analysis, appearance, spreadability, $\mathrm{pH}$, viscosity, in-vitro diffusion study and stability study.
\end{abstract}

Keywords : Solanum Nigrum, HPMC E5, Herbal Gel, Wound Healing

\section{INTRODUCTION}

$[1,2,3,4]$ Many people are choosing plant based medicines or products to improve their health. Solanum nigrum L. belongs to family Solanaceae that has been highly valued food and medicinal plant used since ancient times. Solanum nigrum is one of the proven anti-cancer, anti-tubercular, anti-bacterial as well as anti-inflammatory activities. Traditional societies include always exploited edible wild plants to grant an adequate level of nutrition. Solanum nigrum is an erect, divaricately branched, unarmed annual herb. A decoction of the stalk, leaves and roots of black nightshade is beneficial for wounds and cancerous sores. The juice of herb or an ointment prepared from it is externally applied to cure specific skin problems and tumors. Solanum nigrum contains an alkaloid, steroidal alkaloid as well as steroidal saponins and glycoproteins exhibiting antitumor activity, flavonoids, tannins, saponins, proteins, carbohydrates, coumarins and phytosterols.

\section{Gel}

The word gel derived from "gelatin." A gel defined as the semisolid system consisting of dispersion made up of large molecule or small inorganic particle enclosing and interpenetrated by a liquid. Gel comprised of two phases. It should possess suitable 
anti-microbial to prevent from microbial attack. The topical gel should not be tacky. Ideally, the gelling agent for cosmetic or pharmaceutical use should be safe, inert and should not react with other formulation components. Synthesis, swelling, rheology, structure and aging these are the characteristic of the gel.

\section{Wound:}

The wound may be defined as a disruption of anatomic and cellular continuity of tissue, with or without microbial infection and it produced due to any cut or accident with sharp-edged things or other. The wound may generate due to chemical, thermal, microbial, immunological or physical exploitation to the tissues. The wound is also defined as disruption or damage to the normal anatomical function and structure of the skin.

Open and Closed Wounds are the main types of wounds.

The mechanism of the wound healing process involves

1. Inflammatory mediators and growth factors.

2. Cell-cell and cell-extracellular matrix interactions, which govern

$\checkmark$ Proliferation,

$\checkmark$ Differentiation and

$\checkmark$ Migration.

3. Events which included epithelialization, fibroplasia and angiogenesis

4. Wound contraction

5. Remodelling

\section{METHODS AND MATERIAL}

[5,6] Solanum nigrum extract obtained from Sunpure Extract Pvt. Ltd., New Delhi, HPMC E5, Methyl paraben, Propyl paraben, Propylene glycol and Triethanolamine were obtained from Research fine lab, Mumbai.

\section{Characterizations of Solanum nigrum:}

State: - Solid, amorphous powder

Colour: - Brown

Odour: - Characteristics

\section{Total ash value}

$2 \mathrm{gm}$ of powdered extract was weighed into the dish. Dish supported on a pipe clay triangle placed on a ring of tripod stand. Heated with a burner, using a flame about $2 \mathrm{~cm}$ high and supporting dish about 7 $\mathrm{cm}$ above the flame, powder was heated till vapors almost ceased to be evolved; then lowered the dish and heated more strongly until all the carbon was burnt off. The powder was cooled in desiccator. Weighed the ash and calculated the percentage of total ash with reference to the air dried sample of the crude drug.

Wt. of the empty dish $=\mathrm{X}$ gm

Wt. of drug taken $=\mathrm{Y}$ gm

Wt. of the dish + ash (after complete incineration $)=$ Z gm

Wt. of ash $=(Z-X)$ gm i.e., ' $Y$ ' g of the crude drug gives $(\mathrm{Z}-\mathrm{X}) \mathrm{gm}$ of ash

Therefore $100 \mathrm{gm}$ of the crude drug gives $100 / \mathrm{Y} \times(\mathrm{Z}-$ $\mathrm{X}) \mathrm{gm}$ of ash

Total ash value of sample $=100(\mathrm{Z}-\mathrm{X}) / \mathrm{Y} \%$

The total ash value of Solanum nigrum was found to be $10 \%$.

\subsection{Formulation of gel $^{7}$}

Preparation of gel containing extract $1.5 \mathrm{gm}$ of HPMC E5 was dispersed in $50 \mathrm{ml}$ of distilled water. It was kept aside to swell, which was further stirred to form a gel. $5 \mathrm{ml}$ of distilled water is taken to dissolve 
required quantity of methyl paraben and propyl paraben with the aid of heat on water bath. Solution was cooled and propylene glycol was added to it. Further, required quantity of ethanolic extract Solanum nigrum was mixed to the above mixture and volume made up to $100 \mathrm{ml}$ by adding remaining distilled water. All the ingredients were mixed properly and with continuous stirring. Triethanolamine was added drop wise to the formulation for the adjustment of $\mathrm{pH}$ (6.8-7) and also to obtain a gel at required consistency. The same method was followed for the preparation of control sample. Prepared gel was filled in collapsible tubes and stored at a cool and dry place.

\subsection{Evaluation of $\mathrm{Gel}^{8,9}$}

\section{$\mathrm{pH}$}

The $\mathrm{pH}$ of various gel formulations was determined by using digital $\mathrm{pH}$ meter. One gram of gel was dissolved in $100 \mathrm{ml}$ distilled water and stored for two hours. The measurement of $\mathrm{pH}$ of each formulation was done in triplicate and average values are calculated.

\section{Homogeneity}

After the gels have been set in container, all developed gels were tested for homogeneity by visual inspection. They were tested for their appearance and presence of any aggregates.

\section{Spreadability}

The spreadability of the gel formulations was determined, by measuring the spreading diameter of $1 \mathrm{gm}$ of gel between two horizontal plates $(20 \mathrm{~cm} \times$ $20 \mathrm{~cm}$ ) after one min attached with the weight. Spreadability was calculated using the following formula:

$$
S=\frac{M L}{T}
$$

Where,

$\mathrm{S}=$ Spreadability

$\mathrm{M}=\mathrm{Wt}$. in the pan

$\mathrm{L}=$ Length moved by the glass slide and

$\mathrm{T}=$ Time in second

\section{Viscosity}

The viscosity of the gel formulations was determined using Brookfield viscometer in triplicate with spindle no. 6 at 5, 10, 20, 30 and $50 \mathrm{rpm}$. The average viscosity was found to be $1600,1050,8590,7200$ and 4020 respectively.

\section{In vitro diffusion study}

The diffusion studies of the prepared gels can be carried out in Franz diffusion cell for studying the diffusion pattern of gels through a cellophane membrane. Gel sample (1gm) was taken in cellophane membrane and the diffusion studies were carried out at $37 \pm 1^{\circ}$ temp using $200 \mathrm{ml}$ of phosphate buffer $(\mathrm{pH}$ 7.4) as the dissolution medium. Five milliliters of each sample was withdrawn periodically at $1,2,3,4,5,6,7$ and $8 \mathrm{hr}$ and each sample was replaced with equal volume of fresh dissolution medium. Then the samples were analyzed for the drug content by using phosphate buffer as blank.

\section{FT-IR Spectroscopy:}

FT-IR study is carried out on pure drug as well as on gel formulation. This technique is based upon the simple fact that the substance shows marked selective absorption in the infrared region. After absorption of IR radiations, the molecules of the chemical substance vibrate at many rates of vibration, giving rise to close-packed absorption bands, called as IR absorption spectrum which may extend over a wide wavelength range. Various bands will be present in IR spectrum which will correspond to the characteristic functional groups and bonds present in the chemical substance. It is used to establish the 
structure of unknown compound and analysis of functional group. The sample was analyzed between $4000-400 \mathrm{~cm}^{-1}$.

\section{RESULTS AND DISCUSSION}

The prepared gel formulations were evaluated for various pharmaceutical parameters and results were mentioned in the table. From the results it is clearly say that all the gel formulations showed good gelling property and homogeneity. The herbal gel was prepared and subjected to evaluation of various parameters. The $\mathrm{pH}$ of all the formulations was in the range compatible with normal $\mathrm{pH}$ range of the skin. The gel was brownish in color; with a translucent appearance. All the developed gels were tested for homogeneity by visual inspection for appearance and presence of any lumps, flocculates or aggregates. The homogeneity was found to be good for all formulations. The gel did not produce any irritation upon application to the skin. Spreadability was less variant after performing stability studies from that of the initially prepared gel.

Table 1: Formulation table of herbal gel

\begin{tabular}{|c|c|c|c|c|c|}
\hline Ingredients & F1 & F2 & F3 & F4 & F5 \\
\hline $\begin{array}{c}\text { Solanum nigrum extract } \\
(\mathrm{gm})\end{array}$ & 1 & 1 & 1 & 1 & 1 \\
\hline HPMC E5 (gm) & 1 & 1.2 & 1.5 & 1.7 & 2 \\
\hline Propylene glycol (ml) & 10 & 10 & 10 & 10 & 10 \\
\hline Propyl paraben (gm) & 0.1 & 0.1 & 0.1 & 0.1 & 0.1 \\
\hline Methyl paraben (gm) & 0.2 & 0.2 & 0.2 & 0.2 & 0.2 \\
\hline Glycerine (ml) & 1 & 1 & 1 & 1 & 1 \\
\hline Triethanolamine & Q.S. & Q.S. & Q.S. & Q.S. & Q.S. \\
\hline Distilled water (ml) & Upto100 & Upto100 & Upto 100 & Upto 100 & Upto 100 \\
\hline
\end{tabular}

Table 2: Physical evaluation of gel

\begin{tabular}{|c|c|c|c|c|}
\hline Formulation code & Appearance & $\mathrm{pH}$ & Homogeneity & Spreadability \\
\hline F1 & $\begin{array}{c}\text { Brown, Smooth, } \\
\text { Translucent }\end{array}$ & 6.8 & Homogeneous & 28.6 \\
\hline F2 35 & $\begin{array}{c}\text { Brown, Smooth, } \\
\text { Translucent }\end{array}$ & 6.5 & Homogeneous & 25.4 \\
\hline F4 & $\begin{array}{c}\text { Smooth, Brown } \\
\text { Translucent, }\end{array}$ & 7 & Homogeneous & 21.9 \\
\hline F5 & $\begin{array}{c}\text { Smooth, Brown, } \\
\text { Translucent }\end{array}$ & 7.2 & Homogeneous & 20.4 \\
\hline
\end{tabular}




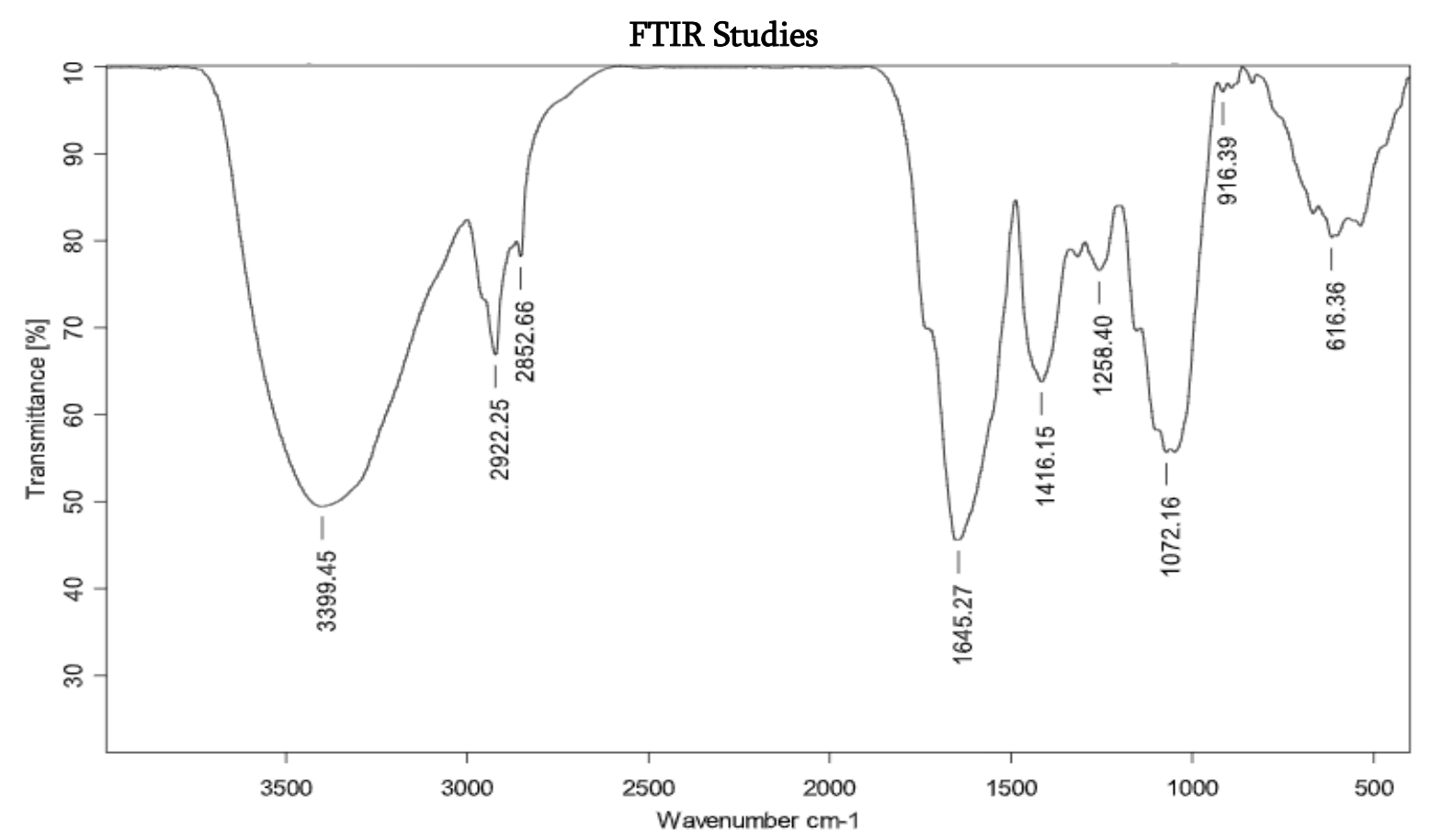

Figure 1: FTIR of Pure Drug

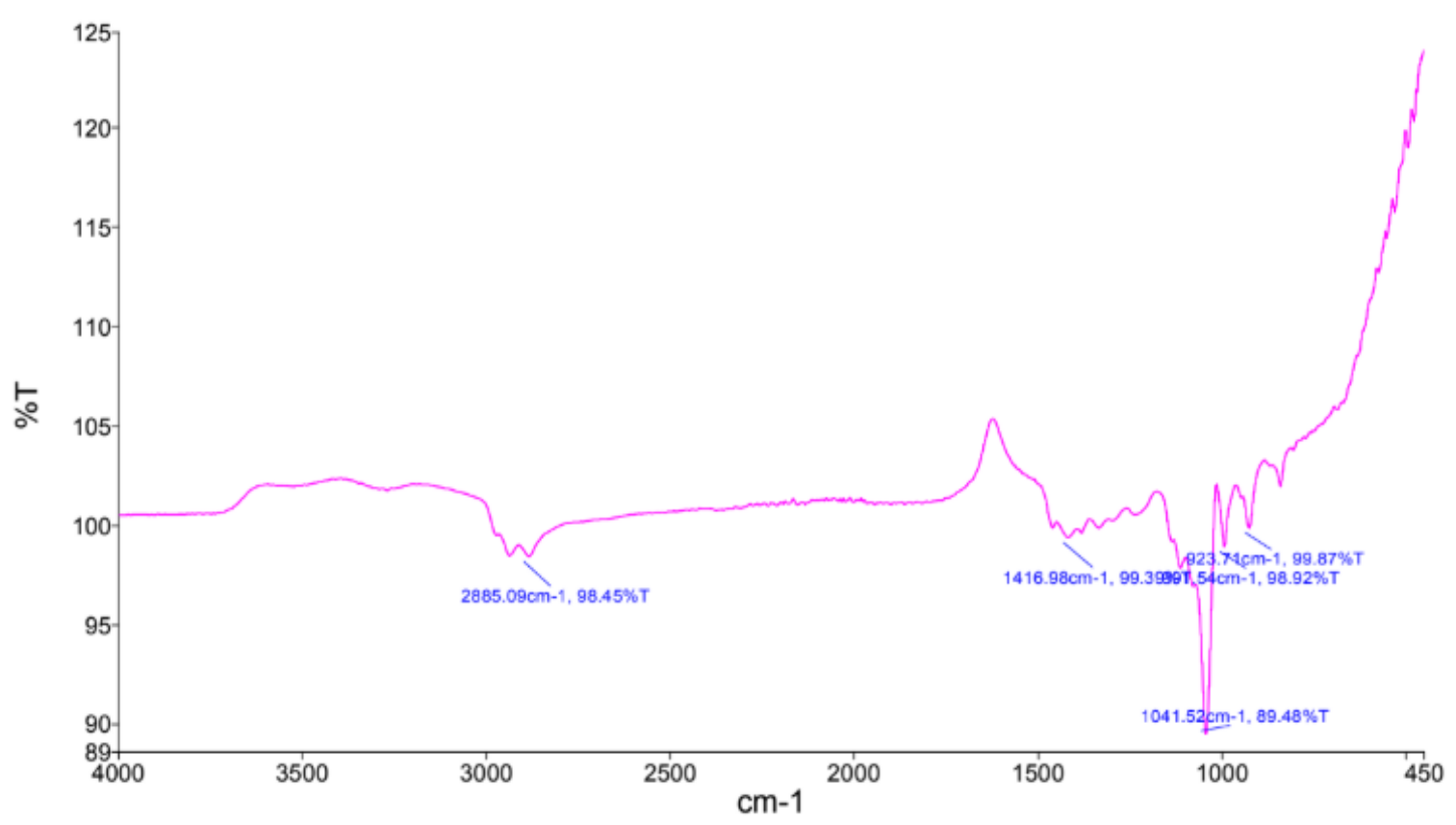

Figure 2: FTIR of gel formulation 
Table 3 : Interpretation of FT-IR of Solanum nigrum and Gel

\begin{tabular}{|c|c|c|c|}
\hline Sr. No & Functional group & Standard peak & Observed peak \\
\hline 1 & N - H Streching & $3400-3250$ & 3399.45 \\
& & & 3939.15 \\
\hline 2 & C-H stretch of the aromatic group & $3000-2850$ & 2922.25 \\
& & & 2852.66 \\
& & & 2885.09 \\
\hline 3 & C=O & $1700-1690$ & 1645.27 \\
\hline 4 & C-C stretching mode & $1500-1300$ & 1416.15 \\
& & & 1416.98 \\
\hline 5 & Aromatic C- C & $1100-1000$ & 1072.16 \\
& & & 1041.52 \\
\hline 6 & C-N & $1250-1020$ & 1258.40 \\
\hline 7 & C - C Bending & & 916.39 \\
& & & 923.71 \\
\hline 8 & C-Br & & 616.36 \\
\hline & & & \\
\hline
\end{tabular}

\section{Calibration of Solanum nigrum extract}

Table 4 : Calibration of Solanum nigrum extract

\begin{tabular}{|c|c|c|}
\hline Sr.no. & Concentration $(\mu \mathrm{g} / \mathrm{ml})$ & Absorbance $(\lambda \max$ observed at $285 \mathrm{~nm})$ \\
\hline 1 & 2 & 0.131 \\
\hline 2 & 4 & 0.233 \\
\hline 3 & 6 & 0.368 \\
\hline 4 & 8 & 0.495 \\
\hline 5 & 10 & 0.599 \\
\hline 6 & 12 & 0.689 \\
\hline
\end{tabular}




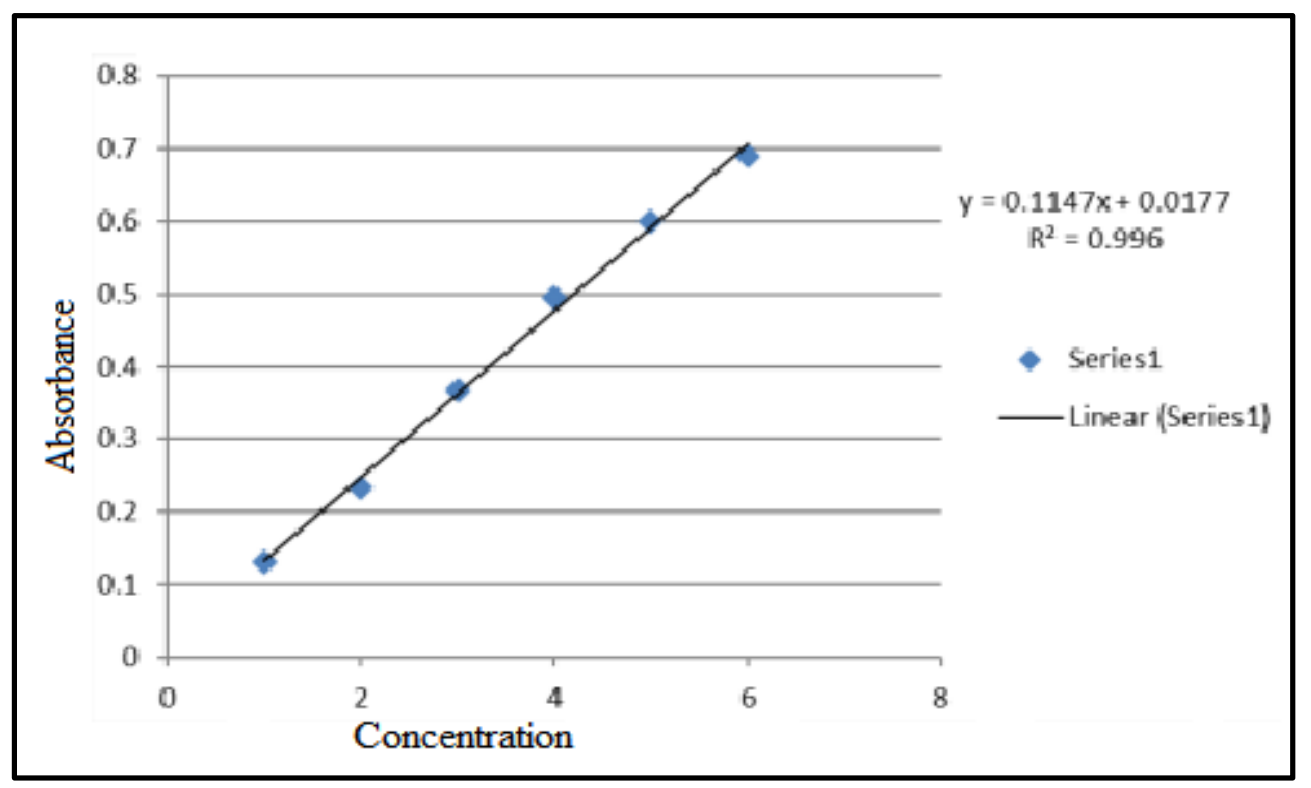

Figure 3: Calibration Curve of solanum nigrum leaf extract

\section{In vitro diffusion study}

The diffusion studies of the prepared gels can be carrying out in Franz diffusion cell for studying the dissolution release of gels through a cellophane membrane. Gel sample (1g) was taken in cellophane membrane and the diffusion studies were carried out at $37 \pm 1^{\circ}$ using $200 \mathrm{ml}$ of phosphate buffer ( $\mathrm{pH} 7.4$ ) as the dissolution medium. Five milliliters of each sample was withdrawn periodically at $1,2,3,4,5,6$, 7 and $8 \mathrm{~h}$ and each sample was replaced with equal volume of fresh dissolution medium. Then the samples were analyzed for the drug content by using phosphate buffer as blank.

Table 5 : Data obtained for In-vitro diffusion study

\begin{tabular}{|c|c|c|c|c|c|}
\hline Time (Hr) & f1 & f2 & f3 & f4 & f5 \\
\hline 0 & 0 & 0 & 0 & 0 & 0 \\
\hline 1 & 32.68 & 36.18 & 38.4 & 36.1 & 32.4 \\
\hline 2 & 44.74 & 46.8 & 49.2 & 45.22 & 46.22 \\
\hline 3 & 53.27 & 54.1 & 57.5 & 52.12 & 52.08 \\
\hline 4 & 66.13 & 65.18 & 68.17 & 64.18 & 61.42 \\
\hline 5 & 70.12 & 72.4 & 75.8 & 71.2 & 68.31 \\
\hline 6 & 75.2 & 76.5 & 80.2 & 72.33 & 71.68 \\
\hline 7 & 78.4 & 79.52 & 85.41 & 75.14 & 74.87 \\
\hline 8 & 80 & 81.43 & 90.11 & 78.2 & 79.5 \\
\hline
\end{tabular}

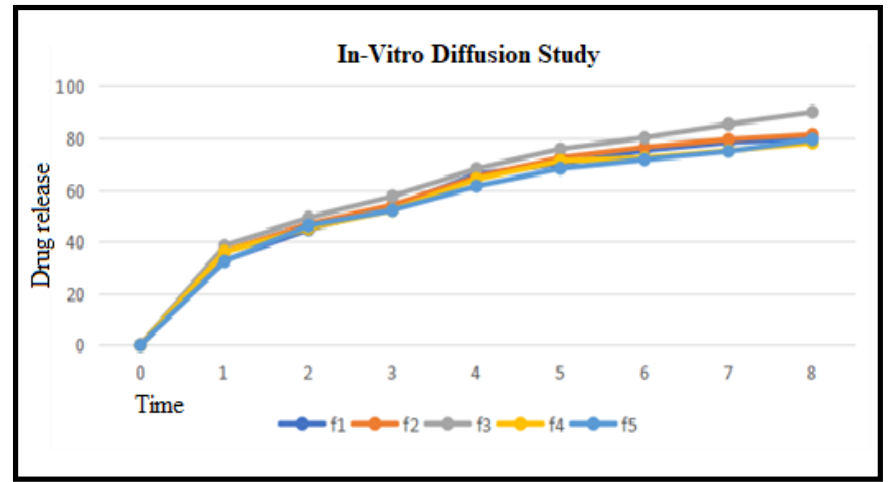

IV.CONCLUSION

This research work was carried out to develop a new topical herbal gel formulation for topical wound healing application. The prepared herbal gel was further evaluated for $\mathrm{pH}$, Viscosity, Spreadability, Invitro diffusion study and Drug-Polymer Compatibility Studies. The gel formulation F3 is optimized and found to have all the desirable properties. The formulation of Solanum nigrum gel provides a good wound healing activity.

\section{REFERENCES}

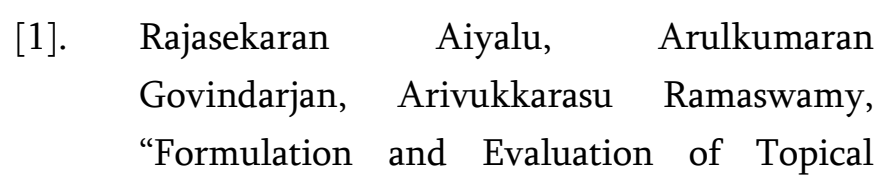


Herbal Gel for the Treatment of Arthritis in Animal Model". Brazilian Journal of Pharmaceutical Sciences July/Sep. 2016: 52(3): 493-507.

[2]. Romana Rashid, Dr. Ghulam Nabi Hajam, Muzaffer Hussain Wani and Dr. Manik Sharma, "Organoleptic Evaluation of the Plant Solanum Nigrum L. of the Family Solanaceae", International Journal of Applied Research 2017: 3(11): 142-145.

[3]. "The Ayurvedic Pharmacopoeia of India", 2(1): 70.

[4]. Jagtap C.Y., Prajapati P. K., Harisha C. R., Shukla V. J., "Micrometric Study and Physicochemical Evaluation of Solanum Nigrum Linn. Leaves", The Journal of Phytopharmacology, 2016: 5(3): 117-121.

[5]. M. Rajathi, D Modilal, R. Anandan, R. Sindhu and M.N. Logeshwari, "Screening of Solanum Nigrum for its Phytochemical and Antimicrobial Activity against Respiratory Tract Pathogens", International Journal of Pure and Applied Zoology, 2015: 3(3): 210215.

[6]. Rajarshi Biswas, "Development and evaluation of some medicinal plant for tyrosinase inhibition and their formulation", Shodhganga : a reservoir of Indian theses, 27 Jun 2018,Chapter - 6: 102-133.

[7]. Jadhav V.D., Talele Swati G., Bakliwal Akshda A., Chaudhari G.N. "Formulation and evaluation of herbal gel containing leaf extract of tridax procumbens", Journal of Pharmaceutical and BioSciences. 2015: 3(3): 65-72.

[8]. Ashni Verma, Sukhdev Singh, Rupinder Kaur, Upendra K Jain, “Topical Gels As Drug Delivery Systems: A Review”, Int. J. Pharm. Sci. Rev. Res., Nov - Dec 2013: 23(2): 374382.
[9]. Loveleen Preet Kaur, Tarun Kumar Guleri, “Topical Gel: A Recent Approach for Novel Drug Delivery", Asian Journal of Biomedical and Pharmaceutical Sciences, 2013, 3(17): 15.

[10]. A. Krishna Sailaja,R. Supraja, "An overall review on topical preparation-gel" Innovat International Journal of Medical \& Pharmaceutical Sciences, 2016, 1(1): 17-20.

[11]. T. Velnar, T. Bailey and V. Smrkolj, "The Wound Healing Process: An Overview of The Cellular and Molecular Mechanisms", The Journal of International Medical Research 2009, 37(5): 1528 - 1542.

[12]. Christine Theoret and Jim Schumacher, "Textbook of Equine Wound Management", Published by John Wiley \& Sons, Inc. 2017: Third Edition, 1-13.

[13]. Shirin Fahimi, Mohammad Abdollahi,Seyed Alireza Mortazavi,Homa Hajimehdipoor,Amir Hossein Abdolghaffari and Mohammad Amin Rezvanfar,"Wound Healing Activity of A Traditionally Used Poly Herbal Product In A Burn Wound Model In Rats", Iran Red Crescent Med J, Sep 2015, 17(9): 1-8.

[14]. Deshpande SM, Upadyaya RR, "Chemical studies of Jasminum auriculatum (Vahl) leaves-II". Springerlink Experientia, May 1968, 24:421.

[15]. Dewangan H., Bais M., Jaiswal V., Verma VK, "Potential wound healing activity of the ethanolic extract of Solanum xanthocarpum schrad and wendl leaves". Pakistan Journal of Pharmaceutical Sciences. Jan 2012, 25(1): 189-194.

[16]. DrissaDiallo, Paulsen BS, A Liljeback TH and Terje E Michaelsen, "Polysaccharides from the roots of Entada africana Guill. et Perr., Mimosaceae, with complement fixing 
activity". Journal of Ethnopharmacology,

February 2001, 74(2): 159-171.

[17]. Dikshit A., Dixit SN. "Cedrus oil - a

promising anti-fungal agent". Indian

Perfumer, 1982, 26(2/4): 216-227.

[18]. Diwan PV., Tillo LD., Kulkarni DR, "Steroid depressed wound healing and Tridaxprocumbens". Indian Journal of Physiology and Pharmacology, 1983, 27(1): 32-36.

\section{Cite this article as :}

Dr. Nagoba Shivappa N., Sonkamble Pallavi S., Sakhare Ram S., Wadulkar Raghunath D., Swami Avinash B., "Formulation and Evaluation of Herbal Gel Containing Solanum Nigrum Extract", International Journal of Scientific Research in Science and Technology (IJSRST), Online ISSN : 2395-602X, Print ISSN : 2395-6011, Volume 6 Issue 4, pp. 83-91, July-August 2019. Available at doi : https://doi.org/10.32628/IJSRST196415 Journal URL : http://ijsrst.com/IJSRST196415 